\title{
HUBUNGAN TEKNIK MENGEDAN DENGAN KEJADIAN RUPTUR PERINEUM PADA IBU BERSALIN DI PUSKESMAS TIBAWA KABUPATEN GORONTALO
}

\author{
Masmuni Wahda Aisya1, Efri Leni Rauf2, Julima Ahaya ${ }^{3}$ \\ Program Studi D-IV Bidan Pendidik Fakultas IImu Kesehatan Universitas Muhammadiyah \\ Gorontalo, 2018 \\ Email: masmuniwahdaaisyah@umgo.ac.id
}

\begin{abstract}
This research aims to know the relationship of engineering straining with the incidence of ruptur the perineum at the birthing mother in Puskesmas Tibawa. This research uses quantitative research design with analytic observational and cross sectional approach. The data collection is done at the same time Sampling techniques used is purposive sampling with the total sample as many 32 respondents mother birthing in Puskesmas Tibawa. Data analysis was done on univariate statistival tests with bivariat and spearmen rank with a level of significance of $\alpha=0.05$. The results of this research show that there is a significant corelation (2-failed) of the techniques with straining relations ruptur the Perineum at the birthing mother in Puskesmas Tibawa $p$ value $=\alpha<0.001$ and 0.05 level of relations force $0.555^{* *}$ or categorized strong.
\end{abstract}

Keywords: Technique Straining, Ruptur Perineum.

\begin{abstract}
ABSTRAK
Penelitian ini bertujuan untuk mengetahui hubungan teknik mengedan dengan kejadian ruptur perineum pada ibu bersalin di Puskesmas Tibawa. Penelitian ini menggunakan metode pendekatan kuantitatif dengan jenis penelitian observasional analitik dan rancangan penelitian cross sectional serta cara pengumpulan data dilakukan sekaligus pada waktu yang bersamaan. Teknik pengambilan sampel menggunakan purposive sampling dengan jumlah sampel sebanyak 32 responden ibu bersalin di Puskesmas Tibawa. Analisa data dilakukan secara univariat dan bivariat dengan uji statistik spearmen rank dengan tingkat kemaknaan $\alpha=0,05$. Hasil penelitian ini menunjukkan bahwa nilai signifikan (2-failed) hubungan teknik mengedan dengan kejadian ruptur Perineum pada ibu bersalin di Puskesmas Tibawa $p$ value $=0,001<\alpha 0,05$ dan tingkat kekuatan hubungan sebesar $0,555^{\star *}$ atau dikategorikan kuat.
\end{abstract}

Kata Kunci : Teknik Mengedan, Ruptur Perineum

\section{PENDAHULUAN}

Ruptur perineum adalah robekan yang terjadi pada saat bayi lahir, baik secara spontan maupun dengan menggunakan alat atau tindakan. Ruptur perineum dibagi menjadi empat tingkatan, yaitu ruptur perineum derajat I, II, III, dan IV. Ruptur perineum umumnya juga terjadi pada persalinan jika kepala janin terlalu cepat lahir, persalinan tidak dipimpin sebagaimana mestinya, jaringan parut pada perineum, dan distosia bahu (Setiyanigrum, 2017).

Di Asia ruptur perineum merupakan masalah yang cukup banyak dalam masyarakat, $50 \%$ dari kejadian ruptur 
perineum didunia terjadi di Asia (Roslena, 2013). Menurut world health organization (WHO) pada tahun 2014 , angka kematian ibu di dunia yaitu 289.000 jiwa. Angka kematian ibu di negara-negara Asia Tenggara yaitu Indonesia sebesar 190/100.000 kelahiran hidup, Brunei Darussalam sebesar 27/100.000 kelahiran hidup dan Malaysia sebesar 29/100.000 kelahiran hidup (Manik, 2016). Berdasarkan profil kesehatan Indonesia tahun 2015, angka kematian ibu di Indonesia sebesar 305/100.000 kelahiran hidup. Angka kematian ibu yang terjadi di Indonesia ini masih di bawah dari negara-negara yang ada di ASEAN (Depkes RI, 2015). Penyebab kematian ibu di Indonesia yakni perdarahan sebesar $30,3 \%$, hipertensi $27,1 \%$, infeksi sebesar $7,3 \%$, dan lain-lain sebesar 40,8\%. Perdarahan postpartum menjadi penyebab utama $40 \%$ kematian ibu di Indonesia. Salah satu hal yang memiliki andil besar dalam menyumbang angka kematian ibu yaitu pada proses persalinan dapat terjadi perdarahan. Perdarahan pada persalinan sering kali mengakibatkan perlukaan jalan lahir. Perlukaan jalan lahir dapat mengenai vulva, perineum, uterus, vagina, dan serviks. Salah satu jenis perlukaan jalan lahir adalah ruptur perineum. Prevalensi ibu bersalin yang mengalami ruptur perineum di Indonesia pada golongan umur 25-30 tahun yaitu $24 \%$ dan pada ibu bersalin usia 32-39 tahun sebesar 62\% (Hermawati et al, 2014). Terkait target dari progr SDGs (sustainable development goals) RPJMN dan RENSTRA di tahun 2019 untuk menurunkan angka kematian ibu sebesar 306/100.000 kelahiran hidup dan pada tahun 2030 sebesar 70/100.000 kelahiran hidup (Anung, 2015).
Pengambilan data awal yang dilakukan pada bulan November tahun 2017 untuk data angka kematian ibu di Provinsi gorontalo tahun 2016 sebesar 223/100.000 kelahiran hidup. Data yang didapatkan dari masing-masing Kabupaten maupun kota di Provinsi Gorontalo untuk kejadian perdarahan yang meningkatkan derajat kematian ibu di masing-masing Kabupaten maupun kota yakni di kota Gorontalo berjumlah 1 jiwa penyebab kematian yaitu ruptur perineum dan rest plasenta, Kabupaten Gorontalo berjumlah 3 jiwa penyebab kematian yaitu ruptur perineum dan rest plasenta, Kabupaten Bone Bolango tidak ada kematian ibu yang disebabkan perdarahan, Kabupaten Boalemo berjumlah 2 jiwa penyebab kematian yaitu rest plasenta, Kabupaten Pohuwato berjumlah 6 jiwa penyebab kematian yaitu ruptur perineum, serta Kabupaten Gorontalo Utara berjumlah 1 jiwa penyebab kematian yaitu atonia uteri. Menurut Setiyaningrum (2017), faktor yang menyebabkan terjadi ruptur perineum yakni kepala janin yang terlalu cepat lahir, persalinan tidak dipimpin sebagaimana mestinya, jaringan parut pada perineum, dan distosia bahu. Menurut Sukarni et al (2014), ruptur perineum lebih sering terjadi pada keadaan-keadaan seperti ukuran janin terlalu besar, proses persalinan yang lama, serta penggunaan alat bantu persalinan (misal forsep). Menurut Prawirohardjo (2014), dampak dari tidak dilaksanakannya penanganan segera untuk kejadian ruptur perineum maka akan menyebabkan ibu mengalami perdarahan yang hebat dengan jumlah perdarahan lebih dari $500 \mathrm{ml}$, sehingga dapat mengakibatkan terjadinya syok hipovolemik pada ibu postpartum. Keadaan seperti ini bila tidak diatasi 
dengan cepat maka akan menyebabkan terjadi kematian pada ibu. Hal ini dapat memicu terjadinya peningkatan mobilitas dan mortalitas ibu.

Berdasarkan hasil survey pendahuluan yang dilakukan pada bulan Desember tahun 2017, peneliti melakukan pengambilan data awal dan wawancara dengan bidan yang bekerja di Puskesmas Tibawa. Data kumulatif yang didapatkan di Puskesmas Tibawa untuk bulan Januari sampai bulan November tahun 2017 yakni data jumlah ibu bersalin spontan normal berjumlah 549 orang ibu bersalin, dan dari jumlah ibu yang bersalin normal tersebut terdapat 195 orang ibu bersalin yang sebagian besar mengalami kejadian ruptur perineum. Untuk kejadian ruptur perineum sebagian besar disebabkan karena teknik mengedan dari ibu yang kurang baik. Sesuai dengan peraturan pemerintah agar ibu dapat menghadapi proses persalinan dengan lancar dan aman, maka diperlukan pemberian informasi, konseling, latihan maupun asuhan kepada ibu untuk bagaimana cara berlatih mengedan yang baik dan benar sesuai dengan teori yang ada. Sehingga pada saat proses bersalin, ibu dapat melewati proses bersalin yang aman dan lancar.

\section{METODOLOGI PENELITIAN}

Penelitian ini menggunakan metode observasional analitik dengan pendekatan cross sectional. Observasional analitik merupakan jenis penelitan yang melihat dan mencoba menggali bagaimana dan mengapa fenomena kesehatan itu terjadi. Cross sectional adalah rancangan penelitian dimana pengambilan data dilakukan bersamaan dengan waktu kejadian (Notoatmodjo, 2012). Penelitian ini populasinya adalah jumlah rata-rata persalinan setiap bulannya yang ada di Puskesmas Tibawa. Jadi, pada bulan Desember tahun 2017 jumlah ibu yang bersalin dan mengalami ruptur perineum sebanyak 37 orang. Teknik pengambilan sampel yang digunakan dalam penelitian ini yakni Purposive Sampling. Pengambilan sampel juga berdasarkan kriteria inklusi dan eksklusi.

HASIL PENELITIAN

Tabel 1. Distribusi frekuensi berdasarkan umur responden

\begin{tabular}{lcc}
\hline \multicolumn{1}{c}{ Umur } & Jlh & $\%$ \\
\hline $\begin{array}{l}\text { Umur RESTI ( } \leq 20 \text { tahun atau } \\
\geq 35 \text { tahun) }\end{array}$ & 10 & 31.2 \\
$\begin{array}{l}\text { Umur WUS (20 sampai } 35 \\
\text { tahun) }\end{array}$ & 22 & 68.8 \\
\hline \multicolumn{1}{c}{ Total } & 32 & 100.0 \\
\hline
\end{tabular}

Sumber: Olahan Data Primer (2018)

Dari Tabel 3 karakteristik responden berdasarkan umur responden yang ada di Puskesmas Tibawa didapatkan dari hasil pengumpulan data menggunakan instrumen penelitian pada 32 responden. Responden yang paling banyak adalah responden dengan umur WUS (20 sampai 35 tahun) yaitu sebanyak 22 orang $(68,8 \%)$. Responden yang paling sedikit adalah responden dengan umur RESTI ( $\leq 20$ tahun atau $\geq 35$ tahun) yaitu sebanyak 10 orang $(31,2 \%)$.

Tabel 2. Distribusi frekuensi berdasarkan pendidikan

\begin{tabular}{lcc}
\hline \multicolumn{1}{c}{ Pendidikan } & Jlh & $\%$ \\
\hline $\begin{array}{l}\text { Pendidikan rendah (tidak lulus SD, } \\
\text { SD, dan SMP) }\end{array}$ & 23 & 71.9 \\
$\begin{array}{l}\text { Pendidikan tinggi (SMA/SMK dan } \\
\text { PT) }\end{array}$ & 9 & 28.1 \\
\hline \multicolumn{1}{c}{ Total } & 32 & 100.0 \\
\hline
\end{tabular}

Sumber: Olahan Data Primer (2018) 
Dari Tabel 2 daiats, karakteristik responden berdasarkan pendidikan terakhir yang ada di Puskesmas Tibawa didapatkan dari hasil pengumpulan data menggunakan instrumen penelitian pada 32 responden. Responden yang paling banyak adalah responden dengan pendidikan rendah (tidak lulus SD, SD, dan SMP) yaitu sebanyak 23 orang $(71,9 \%)$. Responden yang paling sedikit adalah responden dengan pendidikan tinggi (SMA/SMK dan PT) yaitu sebanyak 9 orang $(28,1 \%)$.

Tabel 3. Distribusi frekuensi berdasarkan jumlah paritas

\begin{tabular}{lcc}
\hline \multicolumn{1}{c}{ Paritas } & Jlh & $\%$ \\
\hline Primipara & 18 & 56.2 \\
Multipara & 14 & 43.8 \\
\hline \multicolumn{1}{c}{ Total } & 32 & 100.0 \\
\hline
\end{tabular}

Sumber: Olahan Data Primer (2018)

Dari Tabel 3 diatas, karakteristik responden berdasarkan jumlah paritas di Puskesmas Tibawa didapatkan dari hasil pengumpulan data menggunakan instrumen penelitian pada 32 responden. Responden yang paling banyak adalah responden primipara yaitu sebanyak 18 orang (56,2\%). Responden yang paling sedikit adalah responden multipara yaitu sebanyak 14 orang $(43,8 \%)$.

Tabel 4. Distribusi responden berdasarkan teknik mengedan ibu bersalin pada kala II

\begin{tabular}{|c|c|c|}
\hline Teknik Mengedan & Jlh & $\%$ \\
\hline Tidak Benar & 18 & 56.2 \\
\hline Benar & 14 & 44.8 \\
\hline Total & 32 & 100 \\
\hline
\end{tabular}

Sumber: Olahan Data Primer (2018)

Dari Tabel 4 diatas, distribusi responden berdasarkan teknik mengedan ibu bersalin pada kala II di Puskesmas Tibawa yang didapatkan dari hasil pengumpulan data menggunakan instrumen penelitian kuesioner pada 32 responden. Responden yang paling banyak adalah responden dengan teknik mengedan yang tidak benar yaitu sebanyak 18 orang $(56,2 \%)$. Responden yang paling sedikit adalah responden dengan teknik mengedan yang benar yaitu sebanyak 14 orang $(44,8 \%)$.

Tabel 5. Distribusi responden berdasarkan teknik mengedan pada ibu primipara dengan kejadian ruptur perineum

\begin{tabular}{lccccccc}
\hline \multirow{2}{*}{$\begin{array}{c}\text { Teknik } \\
\text { Mengedan }\end{array}$} & \multicolumn{3}{c}{ Kejadian Ruptur perineum } & \multicolumn{3}{c}{ Total } \\
\cline { 2 - 7 } & $\begin{array}{c}\text { Ruptur } \\
\text { perineum }\end{array}$ & $\%$ & $\begin{array}{c}\text { Tidak ada } \\
\text { Ruptur perineum }\end{array}$ & $\%$ & Jumlah & $\%$ \\
\hline Tidak benar & 9 & 50.0 & 1 & 5.6 & 10 & 55.6 \\
Benar & 3 & 16.7 & 5 & 27.8 & 8 & 44.4 \\
\hline Total & 12 & 66.7 & 6 & 33.3 & 18 & 100.0 \\
\hline
\end{tabular}

Sumber: Olahan Data Primer (2018)

Dari Tabel 5 diatas menunjukkan bahwa dari kejadian ruptur perineum pada ibu primipara bersalin yang dilakukan oleh responden berjumlah 18 orang yang bersalin di Puskesmas Tibawa. Responden yang paling banyak adalah responden dengan teknik mengedan yang tidak benar sebanyak
10 orang $(55,6 \%)$, yang ruptur perineum sebanyak 9 orang $(5,6 \%)$ dan yang tidak ada ruptur perineum sebanyak .1 orang (5,6\%). Responden yang paling sedikit adalah responden dengan teknik mengedan yang benar sebanyak 8 orang $(44,4 \%)$, yang ruptur perineum sebanyak 3 orang $(16,7 \%)$ dan yang 
tidak ada ruptur perineum sebanyak 5 orang $(27,8 \%)$.

Tabel 6. Distribusi responden berdasarkan kejadian ruptur perineum

\begin{tabular}{lcc}
\hline Kejadian Ruptur Perineum & Jlh & $\%$ \\
\hline Ruptur perineum & 21 & 65.6 \\
Tidak ada ruptur perineum & 11 & 34.4 \\
\hline \multicolumn{1}{c}{ Total } & 32 & 100 \\
\hline
\end{tabular}

Sumber: Olahan Data Primer (2018)

Dari Tabel 6 diatas, distribusi responden berdasarkan kejadian ruptur perineum pada ibu bersalin di Puskesmas Tibawa yang didapatkan dari hasil pengumpulan data menggunakan instrumen penelitian kuesioner pada 32 responden. Responden yang paling banyak adalah responden dengan kejadian ruptur perineum yaitu sebanyak 21 orang (65,6\%). Responden yang paling sedikit adalah responden dengan tidak ada kejadian ruptur perineum yaitu sebanyak 11 orang $(34,4 \%)$.

Tabel 7. Hubungan teknik mengedan dengan kejadian ruptur perineum pada ibu bersalin di Puskesmas Tibawa

\begin{tabular}{|c|c|c|c|c|c|c|}
\hline \multirow{2}{*}{$\begin{array}{c}\text { Teknik } \\
\text { Mengedan }\end{array}$} & \multicolumn{4}{|c|}{ Kejadian Ruptur perineum } & \multicolumn{2}{|c|}{ Total } \\
\hline & $\begin{array}{l}\text { Ruptur } \\
\text { perineum }\end{array}$ & $\%$ & $\begin{array}{c}\text { Tidak ada } \\
\text { Ruptur perineum }\end{array}$ & $\%$ & Jumlah & $\%$ \\
\hline Tidak benar & 2 & 6.2 & 16 & 50.0 & 18 & 56.2 \\
\hline Benar & 9 & 28.2 & 5 & 15.6 & 14 & 43.8 \\
\hline Total & 11 & 34.4 & 21 & 65.6 & 32 & 100.0 \\
\hline \multicolumn{7}{|c|}{$P$ value sign (2- failed) : 0.001} \\
\hline Corelation co & ent : $0.555^{*}$ & & & & & \\
\hline
\end{tabular}

Sumber: Olahan Data Primer (2018)

Dari Tabel 7 diatas, menunjukkan bahwa analisis bivariat dari kejadian ruptur perineum pada ibu bersalin yang dilakukan oleh responden berjumlah 32 orang yang bersalin di Puskesmas Tibawa. Responden yang paling banyak adalah responden dengan teknik mengedan yang tidak benar sebanyak 18 orang $(56,2 \%)$, yang tidak ada ruptur perineum sebanyak 2 orang $(6,2 \%)$ dan yang mengalami ruptur perineum sebanyak .16 orang (50,0\%). Responden yang paling sedikit adalah responden dengan teknik mengedan yang benar sebanyak 14 orang $(43,8 \%)$, yang tidak ada ruptur perineum sebanyak 9 orang $(28,2 \%)$ dan yang mengalami ruptur perineum sebanyak 5 orang $(15,6 \%)$.
Dari hasil analisa spearmen rank dari uji nilai output diatas diperoleh nilai signifikasi atau sign. (2-failed) sebesar 0,001 dan kekuatan hubungan diperoleh dari corelation coeficient sebesar $0,555^{\star *}$. Karena nilai sig. (2-failed) $0,001 \leq$ lebih kecil dari derajat kemaknaan $\alpha=0,05$ dan tingkat kekuatan hubungan sebesar $0,555^{* *}$ atau dikategorikan kuat. Jadi, dapat disimpulkan bahwa Ha diterima yang menunjukkan ada hubungan yang signifikan antara hubungan teknik mengedan dengan kejadian ruptur perineum pada ibu bersalin Puskesmas Tibawa.

\section{PEMBAHASAN}

Ruptur perineum terjadi pada hampir semua persalinan pertama dan tidak 
jarang juga pada persalinan berikutnya. Robekan ini dapat dihindarkan atau dikurangi dengan menjaga jangan sampai dasar panggul dilalui oleh kepala janin dengan cepat, sebaliknya kepala janin yang akan lahir sebaiknya tidak ditahan terlampau kuat dan lama, karena hal ini akan menyebabkan asfiksia dan perdarahan dalam tengkorok janin, dan melemahkan otototot dan fasia pada dasar panggul karena diregangkan terlalu lama. Robekan perineum umumnya terjadi digaris tengah dan bisa menjadi luas apabila kepala janin lahir terlalu cepat, sudut arkus pubis lebih kecil dari pada biasa sehingga kepala janin terpaksa lahir lebih kebelakang daripada biasa, kepala janin melewati pintu bawah panggul dengan ukuran yang lebih besar daripada sirkumferensia suboksipito-bregmatika, atau anak dilahirkan dengan pembedahan vaginal (Setiyaningrum, 2017).

Menurut Ardiani (2015), teknik mengedan yang baik dan benar sesuai dengan asuhan persalinan normal (APN) tahun 2013, yakni dianjurkan ibu untuk mengedan mengikuti dorongan alamiahnyaselama kontraksi, beritahukan untuk tidak menahan napas saat mengedan, minta untuk berhenti mengedan dan beristirahat di antara kontraksi, jika ibu berbaring miring atau setengah duduk, ia akan lebih mudah untuk mengedan jika lutut ditarik ke arah dada dan dagu ditempelkan dada, minta ibu untuk tidak mengangkat bokong saat mengedan, tidak diperbolehkan untuk mendorong fundus untuk membantu kelahiran bayi, ibu harus tetap tenang dan rileks, penolong persalinan tidak boleh mengatur posisi mengedan, penolong persalinan harus memfasilitasi ibu dalam memilih sendiri posisi mengedan dan menjelaskan alternatif-alternatif posisi mengedan yang dipilih ibu tidak efektif.

\section{Teknik Mengedan Ibu Bersalin pada Kala II}

Tabel 4 menunjukkan teknik mengedan ibu bersalin pada kala II. Penelitian yang dilakukan di Puskesmas Tibawa, lebih didominasi oleh teknik mengedan ibu bersalin yang tidak benar sebanyak 18 orang $(56,2 \%)$ dari responden yang berjumlah 32 orang. Teknik mengedan adalah gabungan dari rasa dan keinginan dari ibu yang kuat serta refleks yang muncul disebabkan oleh adanya tekanan bayi pada vagina ibu selama ada kontraksi yang terjadi pada ibu bersalin memasuki kala II persalinan. Mengedan adalah sifat kekuatan yang dihasilkan mirip seperti yang terjadi pada saat buang air besar tetapi biasanya intensitasnya jauh lebih besar setelah serviks terbuka lengkap kekuatan yang sangat penting pada ekspulsi janin yang dihasilkan oleh peningkatan tekanan intra abdomen yang diciptakan oleh kontrasepsi otototot abdomen (Rukiyah, 2009). Menurut Simkin et al (2008), teknik mengedan pada kala II yakni mengedan spontan, mengedan dengan pengarahan sendiri, dan mengedan dengan diarahkan.

Adapun teknik mengedan pada ibu bersalin memasuki kala II persalinan yang termuat dalam buku JNPK-KR (Jaringan Nasional Pelatihan KlinikKesehatan) Tahun 2007, diantaranya: Menurut JNPK-K (jaringan nasional pelatihan klinik-kesehatan) tahun 2007, dorongan pada fundus meningkatkan resiko distosia bahu dan rupture uteri. Cegah setiap anggota keluarga yang mencoba melakukan dorongan pada fundus. Untuk mengkoordinasikan semua kekuatan menjadi optimal saat 
his dan mengedan dapat dilakukan halhal sebagai berikut: a) ibu mengedan dimulai saat persalinan memasuki kala ke-II persalinan; b) ibu mengikuti perintah bidan untuk mengedan pada saat ada kontraksi; c) ibu menarik napas panjang, pada saat mulai mengedan dan ibu mengatur nafas dengan baik dengan cara membuang napas sedikit demi sedikit; d) ibu mengangkat kepala saat mengedan dan merangkul kedua pahanya, sehingga dapat menambah pembukaan pintu bawah panggul; e) ibu berkonsentrasi mengedan pada daerah perut (bukan pada otot leher); f) mata ibu tetap terbuka dan arah pandangan ibu ke perut pada saat mengedan; g) kaki ibu dilemaskan dan tidak tegang pada saat apapun posisi melahirkan ibu; h) ibu menutup mulut, kemudian mengedan ke daerah perut; i) ibu berhenti mengedan pada saat penolong persalinan memerintahkan berhenti; dan j) ibu dapat beristrirahat di sela periode mengedan dengan bernapas cepat (panting), kemudian menghembuskan napas pendek-pendek dari mulut dan mengulangi teknik mengedan yang baik sesuai dengan anjuran bidan.

Asumsi peneliti berdasarkan hasil penelitian yakni bahwa teknik mengedan pada kala II akan berpengaruh pada kejadian ruptur perineum pada ibu bersalin. Karena jika teknik mengedan salah maka ruptur perineum juga bisa lebih berat dibandingkan dengan teknik mengedan secara benar. Hal ini disebabkan jika cara seseorang dalam mengatur nafas saat mengedan dan juga cara melakukan dorongan saat mengedan. Sehingga diperlukan pengetahuan ibu dan bantuan dari penolong agar ibu dapat mengedan dengan benar untuk mengurangi ruptur perineum. Hasil penelitian diatas sejalan dengan hasil penelitian yang dilakukan oleh Triyanti et al (2017), yang berjudul faktor-faktor yang berhubungan dengan kejadian ruptur perineum pada ibu bersalin di BPM Fauziah Hatta Palembang dengan kesimpulan penelitian yaitu teknik mengedan ibu bersalin dari 40 responden yang melakukan teknik mengedan kurang baik sebanyak 24 responden $(60 \%)$.

\section{Kejadian Ruptur perineum pada Ibu Bersalin}

Tabel 6 menunjukkan kejadian ruptur perineum pada ibu bersalin. Penelitian yang dilakukan di Puskesmas Tibawa, lebih didominasi oleh adanya kejadian ruptur perineum derajat I dan II yakni sebanyak 21 orang $(65,6 \%)$ dari responden yang berjumlah 32 orang. Ruptur perineum adalah robekan yang terjadi pada saat bayi lahir, baik secara spontan maupun dengan menggunakan alat atau tindakan. Ruptur perineum dibagi menjadi empat tingkatan, yaitu ruptur perineum derajat I, II, III, dan IV. Ruptur perineum umumnya juga terjadi pada persalinan jika kepala janin terlalu cepat lahir, persalinan tidak dipimpin sebagaimana mestinya, jaringan parut pada perineum, dan distosia bahu (Setiyanigrum, 2017).

Asumsi peneliti berdasarkan hasil penelitian yakni masih tingginya angka kejadian ruptur perineum derajat I dan II di Puskesmas Tibawa disebabkan karena kurangnya komunikasi yang baik antara penolong persalinan dan ibu bersalin. Seperti pada saat belum ada pembukaan lengkap ibu sebenarnya tidak dianjurkan untuk mengejan tetapi ibu terus saja mengejan sehingga pada saat waktunya harus mengejan ibu sudah kelelahan sehingga ibu tidak kooperatif saat proses persalinan 
berlangsung. Selain itu pada saat penelitian ini di lakukan respondennya lebih banyak primipara dan pada umumnya mereka belum mempunyai pengalaman dengan proses kelahiran sebelumnya, belum mengetahui teknik mengejan yang benar, posisi persalinan yang benar dan perineum pada primipara cenderung kaku dan tidak elastis sehingga mudah sekali terjadi rupture.

Hasil penelitian diatas sejalan dengan hasil penelitian yang dilakukan oleh Prawitasari et al (2015), yang berjudul penyebab terjadinya ruptur perineum pada persalinan normal di RSUD Muntilan Kabupaten Magelang dengan kesimpulan penelitian yaitu kejadian ruptur perineum berdasarkan klasifikasi derajat ruptur perineum dari 41 kasus ruptur perineum terbanyak terjadi pada derajat I dan 2 yakni sebanyak 24 kasus $(58,54 \%)$.

\section{Hubungan Teknik Mengedan dengan Kejadian Ruptur perineum di Puskesmas Tibawa}

Teknik mengedan pada ibu bersalin kala II dalam penelitian ini dikategorikan menjadi 2, yaitu teknik mengedan yang benar dan tidak benar. Mengukur teknik mengedan pada ibu bersalin kala II dalam penelitian ini dilakukan dengan wawancara pada ibu sebelum ibu memasuki kala II dan melakukan observasi dengan menggunakan instrumen penelitian berupa checklist sekaligus menilai apakah teknik mengedan yang dilakukan oleh ibu sesuai dengan pedoman atau tidak. Hasil analisis statistika non parametrik dengan uji Spearmen rank dan menggunakan spss 16 diperoleh nilai signifikasi atau sign. (2-failed) sebesar 0,001 dan kekuatan hubungan diperoleh dari corelation coeficient sebesar
0,555**. Karena nilai sig. (2-failed) $0,001 \leq$ lebih kecil dari derajat kemaknaan $\alpha$ 0,05 dan tingkat kekuatan hubungan sebesar $0,555^{* *}$ atau dikategorikan kuat. Jadi, dapat disimpulkan bahwa $\mathrm{Ha}$ diterima yang menunjukkan ada hubungan yang signifikan antara hubungan teknik mengedan dengan kejadian ruptur perineum pada ibu bersalin Puskesmas Tibawa.

Hasil penelitian yang dilakukan di Puskesmas Tibawa didapatkan bahwa teknik mengedan yang tidak benar dan mengalami ruptur perineum masih tinggi yakni sebanyak 16 responden $(50,0 \%)$. Hal ini dikarenakan pada proses persalinan kala II (pengeluaran bayi) pada fleksus frankenhauser disekitar mulut rahim terjadi rangsangan sehingga menimbulkan reflek ingin mengedan, disertai dengan adanya kontraksi yang dapat menimbulkan kekuatan untuk melahirkan bayi. Jika pada saat ini ibu dapat mengendalikan antara kontraksi dengan kekuatan mengedan maka hasilnya dapat mempercepat proses persalinan, namun sebaliknya jika pada saat adanya kontraksi berlangsung ibu tidak dapat mengendalikannya dengan melakukan teknik mengedan yang salah maka akan terjadi ruptur perineum. Sehingga diperlukan pimpinan dari penolong yang maksimal agar ibu dapat mengedan dengan benar untuk mengurangi kejadian ruptur perineum.

Hasil penelitian juga masih didapatkan teknik mengedan yang benar juga masih terdapat ruptur perineum yaitu sebanyak 5 responden $(15,6 \%)$. Hal ini dikarenakan sebagian ibu bersalin mengalami partus presipitatus (persalinan yang berlangsung cepat) yang tidak dikendalikan dan tidak ditolong dengan 
baik oleh petugas kesehatan, pasien tidak mampu berhenti mengedan. Persalinan diselesaikan secara tergesagesa dengan dorongan fundus berlebihan, oedema dan kerapuhan pada perineum, pimpinan persalinan yang salah, dan persalinan pervaginam dilakukan dengan bantuan mengedan. Asumsi peneliti kecermatan penolong persalinan pada saat memimpin ibu mengedan dan kepatuhan klien pada saat kepala sedang membuka jalan lahir sangatlah penting untuk menghindari terjadinya ruptur perineum. Kerja sama yang baik antara penolong persalinan dan klien dilakukan pada saat antenatal care atau pada saat pelaksanaan kelas ibu hamil. Sehingga antara klien dan penolong akan terjalin suatu hubungan emosional pada saat proses persalinan. Seorang klien akan merasa lebih nyaman dan menurut apa yang dianjurkan oleh penolong pada saat proses persalinan.

Menurut Azizah et al (2017), mengedan adalah respon alami yang normal terhadap mekanisme refleks akibat dari kontraksi yang semakin kuat. Adanya kontraksi yang kuat disertai dengan teknik mengedan yang benar akan membantu mempercepat proses persalinan, sehingga dapat menghindari kejadian asfiksia pada bayi baru lahir serta mengurangi kejadian ruptur perineum, kareana jika mengedan yang tidak terkontrol dapat meningkatkan resiko terjadinya ruptur perineum. Selain dikarenakan faktor dari teknik mengedan yang tidak benar, adapun kemungkinan faktor lain yang menyebabkan terjadinya ruptur perineum diantaranya yakni dari segi umur responden. Umur responden dalam penelitian ini lebih didominasi oleh umur WUS (20 sampai 35 tahun) sebanyak $68,8 \%$. Wanita usia subur disebut sebagai masa dewasa dan disebut juga masa reproduksi, dimana pada masa itu diharapkan orang telah mampu untuk memecahkan masalahmasalah yang dihadapi dengan tenang secara emosional, dalam merawat kesehatan reproduksinya (Pinem, 2009). Asumsi peneliti meskipun umur ibu normal atau termasuk dalam kategori wanita usia subur (WUS) apabila tidak berolahraga dan tidak rajin bersenggama dapat mengalami laserasi perineum. Kelenturan jalan lahir berkurang apabila calon ibu yang kurang berolahraga atau genetalianya sering terkena infeksi. Infeksi akan mempengaruhi jaringan ikat dan otot dibagian bawah serta membuat kelenturannya hilang karena infeksi dapat membuat jalan lahir kaku. Hal ini juga dipengaruhi oleh keelastisitasan perineum sehingga akan mudah terjadinya robekan jalan lahir atau laserasi perineum, oleh karena itu bayi yang mempunyai lingkar kepala maksimal tidak akan dapat melewatinya sehingga menyebabkan laserasi perineum. Hasil penelitian diatas sejalan dengan hasil penelitian yang dilakukan oleh Absari (2017), yang berjudul faktorfaktor yang mempengaruhi kejadian ruptur perineum pada persalinan normal di BPM Wayan Witri Sleman Yogyakarta dengan kesimpulan penelitian yaitu kejadian ruptur perineum berdasarkan umur dari 41 kasus ruptur perineum mayoritas pada kelompok umur 20 sampai 35 tahun yakni sebanyak 33 kasus $(80,5 \%)$.

$$
\begin{array}{ccc}
\text { Teknik } & \text { mengedan } & \text { dapat } \\
\text { mempengaruhi } & \text { terjadinya } & \text { ruptur }
\end{array}
$$
perineum pada ibu bersalin spontan. Pada saat persalinan bidan dapat memberikan asuhan dengan mengajarkan pada ibu untuk melakukan teknik mengedan yang benar yakni 
pada saat terjadi kontraksi ibu dianjurkan untuk mengikuti dorongan secara alami dan pada saat mengedan ibu tidak menahan pernapasaanya. Pada saat mengedan dipuncak kontraksi ibu bersalin tidak diperbolehkan untuk mengangkat bokong. Pada kala II yaitu kala pengeluaran terjadi karena adanya kontraksi yang kuat dan sering, sehingga saat his atau kontraksi terjadi tekanan pada otot dasar panggul, yaitu secara sepontan dapat menimbulkan rasa ingin mengedan, sehingga menyebabkan perineum menonjol serta menjadi lebar dan anus membuka, diikuti labia minora dan mayora, kemudian kepala janin yang tampak pada vulva. Disaat inilah ruptur perineum dapat terjadi terutama pada persalinan primigravida serta melakukan teknik mengedan yang salah (Azizah et al, 2017).

Menurut Hermawati et al (2014), Pendidikan dapat mempengaruhi seseorang termasuk juga perilaku seseorang akan pola hidup terutama dalam memotivasi untuk sikap berperan serta dalam pembangunan pada umumnya makin tinggi pendidikan seseorang makin mudah menerima informasi. Pendidikan berarti bimbingan yang diberikan seseorang terhadap perkembangan orang lain menuju kearah cita-cita tertentu yang menentukan manusia berbuat dan mengisi kehidupan untuk mencapai keselamatan dan kebahagiaan. Faktor pendidikan kemungkinan menjadi salah satu penyebab dimana terjadinya ruptur perineum pada ibu bersalin dengan kategori lebih didominasi oleh pendidikan rendah sebesar $71,9 \%$. Pendidikan yang rendah sangat mempengaruhi seseorang termasuk juga perilaku seseorang akan pola hidup terutama dalam pengetahuan juga memotivasi untuk sikap berperan serta dalam pembangunan. Pendidikan rendah (tidak lulus SD, SD dan SMP) hal ini disebabkan karena sebagian besar responden adalah orang pedesaan yang cenderung memiliki pemikiran lebih baik bekerja menghasilkan uang dari pada melanjutkan sekolah yang cenderung menghabiskan uang banyak untuk biaya pendidikan. Hasil penelitian diatas sejalan dengan hasil penelitian yang dilakukan oleh Aswad (2012), yang berjudul gambaran angka kejadian ruptur perineum tingkat I, II dan III di RSUD Syekh Yusuf Gowa Periode Januari sampai Desember tahun 2011 dengan kesimpulan penelitian yaitu kejadian ruptur perineum berdasarkan tingkat pendidikan dari 328 responden yang mengalami ruptur perineum terbanyak dengan pendidikan rendah (SD dan SMP) sebanyak 226 responden $(68,8 \%)$.

Faktor paritas kemungkinan juga dapat mengakibatkan terjadinya kejadian ruptur perineum hal ini disebabkan responden lebih didominasi oleh responden primipara sebesar $56,2 \%$. Paritas merupakan jumlah anak yang pernah dilahirkan oleh ibu, baik hidup ataupun mati, tetapi bukan aborsi (Suciana, 2016). Asumsi peneliti untuk kategori ibu yang belum pernah memiliki anak mempunyai perineum yang utuh dan kaku. Pada saat kepala janin lahir primipara tidak dapat menahan regangan yang kuat sehingga robek pada pinggir depannya. Luka-luka biasanya ringan tetapi kadang-kadang terjadi juga luka yang luas dan berbahaya. Sebagai akibat persalinan terutama pada seorang primipara, biasa timbul luka pada vulva di sekitar introitus vagina yang biasanya tidak 
dalam akan tetapi kadang-kadang bisa timbul perdarahan banyak. Sedangkan pada multipara tidak utuh, longgar dan lembek. Pada saat akan melahirkan kepala janin perineum harus ditahan, bila tidak ditahan perineum akan robek terutama pada primigravida. Dengan perineum yang masih utuh pada primigravida akan mudah terjadi robekan perineum. ibu yang melahirkan pertama kali mempunyai risiko terjadi ruptur perineum dibandingkan dengan seorang ibu yang melahirkan lebih dari 1 kali. Seorang wanita yang sudah mempunyai 3 orang anak dan terjadi kehamilan lagi keadaan kesehatannya akan mulai menurun. Paritas 2-3 merupakan paritas yang paling aman ditinjau dari terjadinya komplikasi kehamilan dan persalinan yang dapat meningkatkan angka kematian ibu. Hasil penelitian diatas sejalan dengan hasil penelitian yang dilakukan oleh Lailatri (2013), yang berjudul hubungan paritas dengan kejadian ruptur perineum pada ibu bersalin di RSUD Dr. Wahidin Sudirohusodo Mojokerto dengan kesimpulan penelitian yaitu kejadian ruptur perineum berdasarkan paritas dari 41 kasus ruptur perineum 230 responden mayoritas pada ibu primipara yakni sebanyak 83 responden kasus $(36,1 \%)$.

Menurut perdarahan penyebab utama $40 \%$ kematian ibu di Indonesia. Jalan lahir merupakan penyebab kedua perdarahan setelah atonia uteri yang terjadi pada hampir persalinan pertama dan tidak jarang juga pada persalinan berikutnya. Pada seorang primipara atau orang yang baru pertama kali melahirkan ketika terjadi peristiwa "kepala keluar pintu". Pada saat ini seorang primipara biasanya tidak dapat tegangan yang kuat ini sehingga robek pada pinggir depannya. Luka-luka biasanya ringan tetapi kadang-kadang terjadi juga luka yang luas dan berbahaya. Sebagai akibat persalinan terutama pada seorang primipara, biasa timbul luka pada vulva di sekitar introitus vagina yang biasanya tidak dalam akan tetapi kadang-kadang bisa timbul perdarahan banyak. Ruptur perineum terjadi pada hampir semua persalinan pertama dan tidak jarang juga pada persalinan berikutnya. Robekkan ini dapat dihindarkan atau dikurangi dengan menjaga jangan sampai dasar panggul dilalui oleh kepala janin dengan cepat, sebaliknya kepala janin yang akan lahir sebaiknya tidak ditahan terlampau kuat dan lama, karena hal ini akan menyebabkan asfiksia dan perdarahan dalam tengkorok janin, dan melemahkan otototot dan fasia pada dasar panggul karena diregangkan terlalu lama. Robekan perineum umumnya terjadi digaris tengah dan bisa menjadi luas apabila kepala janin lahir terlalu cepat, sudut arkus pubis lebih kecil daripada biasa sehingga kepala janin terpaksa lahir lebih kebelakang daripada biasa, kepala janin melewati pintu bawah panggul dengan ukuran yang lebih besar daripada sirkumferensia suboksipito-bregmatika, atau anak dilahirkan dengan pembedahan vaginal (Setiyaningrum, 2017).

Ruptur perineum merupakan kejadian robeknya otot perineum selama proses persalinan. Robekan biasanya terjadi di serviks, vagina sampai ke otot perineum. Sebagian ibu melahirkan pasti akan mengalami ruptur perineum, baik yang spontan maupun dengan cara episiotomy. Semakin besar ukuran kepala bayi dan semakin cepat keluarnya kepala dari jalan lahir maka robekan akan semakin lebar. Ruptur 
perineum sering kali menyebabkan perdarahan pasca persalinan Akibat langsung dari ruptur perineum adalah dapat terjadi perdarahan. Kesalahan dalam menjahit akan menimbulkan inkontinensia alvi (proses defekasi yang tidak dapat ditahan) karena sfingterani tidak terjahit dengan sempurna, fistula rektovagina, introitus vagina menjadi longgar sehingga akan menimbulkan keluhan dalam hubungan seksual. Upaya yang dapat dilakukan dalam menurunkan kejadian ruptur perineum antara lain dengan senam hamil dan pertolongan persalinan yang aman. Senam hamil dapat dilakukan mulai kehamilan 28 minggu dapat membantu untuk melenturkan otot perineum dan membantu proses pernafasan sehingga diharapkan dapat mengurangi kejadian rupture pada perineum (Irawati, 2017).

Hasil penelitian ini sama dengan hasil penelitian yang dilakukan oleh Herdiani et al (2013), yang menyatakan bahwa teknik mengedan yang tidak benar dengan kejadian ruptur perineum pada ibu bersalin yang ada di BPS "N" Padang Panjang pada bulan Maret s/d Mei Tahun 2013 sebesar 71,9\%. Hal dikarenakan jika salah teknik meneran maka ruptur perineum juga bisa lebih berat dibandingkan dengan teknik meneran yang benar. Hal ini disebabkan oleh cara seseorang dalam mengatur nafas saat mengedan dan juga cara melakukan dorongan saat menran. Sehingga diperlukan pimpinan maksimal penolong agar ibu dapat mengedan dengaan benar untuk mengurangi kejadian ruptur perineum. Sementara itu responden yang lain mengalami ruptur perineum karena dipengaruhi anak besar.

\section{PENUTUP}

Kesimpulan
Kesimpulan dari teknik mengedan dengan kejadian ruptur perineum pada ibu bersalin di Puskesmas Tibawa adalah sebagai berikut:

1. Ibu bersalin di Puskesmas Tibawa didapatkan 32 responden teknik mengedan yang tidak benar pada kala II sebanyak 18 orang $(56,2 \%)$.

2. Ibu bersalin di Puskesmas Tibawa didapatkan 32 responden kejadian ruptur perineum sebanyak 21 orang $(65,6 \%)$.

3. Adanya hubungan yang signifikan antara hubungan teknik mengedan dengan kejadian ruptur perineum pada ibu bersalin Puskesmas Tibawa dilihat dari hasil analisis statistika non parametrik dengan uji Spearmen rank dan menggunakan spss 16 diperoleh nilai signifikasi atau sign. (2-failed) sebesar 0,001 dan kekuatan hubungan diperoleh dari corelation coeficient sebesar $0,555^{\star *}$. Karena nilai sig. (2-failed) 0,001 $\leq$ lebih kecil dari derajat kemaknaan $\alpha$ 0,05 dan tingkat kekuatan hubungan sebesar $0,555^{\star *}$ atau dikategorikan kuat.

\section{Saran}

1. Bagi institusi pendidikan

Penelitian ini dapat dijadikan sebagai acuan materi pembelajaran yang terbaru dalam mengembangkan ilmu kebidanan tentang teknik mengedan dengan kejadian ruptur perineum pada ibu bersalin serta sebagai dokumen dan bahan tambahan sumber bacaan di Universitas Muhammadiyah Gorontalo dan sumber masukkan dalam bidang ilmu terkait.

2. Bagi masyarakat (Ibu hamil dan bersalin)

Ibu hamil maupun bersalin terutama untuk ibu primigravida (hamil anak 


\begin{abstract}
yang pertama) hendaknya menghindari stress agar tidak menyebabkan persalinan berlangsung lama dan juga perbanyak mencari informasi tentang bagaimana proses persalinan dapat berlangsung dengan cepat aman dan sehat terutama bagi ibu dan juga bayi. Ibu hamil juga diharapkan untuk dapat melakukan massase perineum agar ibu dapat mempunyai perineum yang elastis sehingga dapat mengurangi resiko terjadinya ruptur perineum.
\end{abstract}

3. Tenaga kesehatan (bidan) dan Puskesmas Tibawa

a. Meningkatkan kinerja yang cukup baik dalam membimbing dan mengarahkan kepada ibu-ibu hamil maupun yang bersalin tentang bagaimana teknik mengedan yang baik dan benar.

b. Bidan juga diharapkan dapat bekerjasama dengan ibu dalam proses persalinan dan lebih memperhatikan faktor-faktor

\section{DAFTAR PUSTAKA}

Anung, 2015. Kesehatan dalam Kerangka Sustainable

Development Goals (SDGs). Jakarta: Dirjen Bina Gizi KIA. Hal: 23-24

Depkes RI. 2007. Jaringan Nasional Pelatihan Klinik-Kesehatan (JNPK-K). Jakarta: Departemen Kesehatan Republik Indonesia

Depkes RI. 2015. Profil Kesehatan Indonesia. Jakarta: Depkes RI. Hal: 103-128

Puskesmas Tibawa. 2017. Profil Puskesmas Tibawa. Gorontalo

Setiyaningrum, E. 2017. Asuhan Kegawatdaruratan Maternitas Asuhan Kebidanan Patologi Revisi resiko yang dapat mempengaruhi kejadian ruptur perineum sehingga kejadian ruptur perineum dapat dicegah.

c. Bidan dalam pelaksanaan kelas ibu hamil memberikan pengetahuan kepada ibu hamil tentang kesiapan fisik dan memberikan konseling sekaligus mengajarkan tentang cara - cara mengedan dengan teknik yang benar pada saat menghadapi proses persalinan yang dinanti.

4. Bagi peneliti selanjutnya

Penelitian ini hanya membahas tentang dari segi faktor maternal (individu) yang berfokus pada teknik mengedan terhadap kejadian ruptur perineum. Sedangkan, faktor maternal (individu) yang lain, faktor janin serta faktor penolong belum diteliti. Sehingga perlu dilakukan penelitian selanjutnya tentang faktor maternal (individu), faktor janin dan faktor penolong tersebut.

Jilid 1. Jakarta: In Media. Hal:7484

Hermawati, T., Sucipto, E., Andari, D.I. 2014. Hubungan Tingkat Pengetahuan Cara Mengedan yang Benar dengan Terjadinya Ruptur perineum pada Ibu Bersalin di BPM Ny. M Slerok Kota Tegal. Progr Studi D-III Kebidanan. Politeknik Kesehatan Harapan Bersama. Jurnal Kebidanan, Vol. 1 Hal: 87-90

Sukarni, I., Sudarti. 2014. Patologi Kehamilan, Persalinan, Nifas dan Neonatus Resiko Tinggi. Yogyakarta: Nuha Medika. Hal: 92-98 
Notoatmodjo, S. 2012. Metodologi Penelitian Kesehatan. Jakarta: Rineka Cipta. Hal: 37-201

Rukiyah, A. 2009. Asuhan Kebidanan II (Persalinan). Jakarta: TIM. Hal: 30 Triyanti et al. 2017. Faktor-Faktor yang Berhubungan dengan Kejadian Ruptur perineum padalbu Bersalin di BPM Fauziah Hatta Palembang 2017. Program Studi Kebidanan. STIK Bina Husada Palembang.
Jurnal Kebidanan. Vol. 5. No. 1. Hal: 152-159

Azizah, N., Devi, S.A. 2017. Efektivitas Teknik Meneran terhadap Pencegahan Ruptur perineum Spontan pada Ibu Bersalin Primigravida di BPM Sidoarjo. Fakultas IImu Kesehatan. Prodi Kebidanan. Universitas Muhammadiyah Sidoarjo. Jurnal Kebidanan, Vol.1, Hal: 169-172

Irawati, D. 2017. Faktor yang Berhubungan dengan Ruptur perineum di Puskesmas Puri Kabupaten Mojokerto. Prodi Kebidanan. STIKES Majapahit. Jurnal Kebidanan. Vol. 1 Hal: 227-234 